\title{
BMJ Open A cross-sectional study of hyponatraemia among elderly patients with heart failure in Uganda
}

\author{
Harriet Nankabirwa, ${ }^{1}$ Robert Kalyesubula, ${ }^{1}$ Isaac Ssinabulya, ${ }^{1}$ Elly T Katabira, ${ }^{1}$ \\ Robert G Cumming ${ }^{2}$
}

To cite: Nankabirwa $\mathrm{H}$, Kalyesubula R, Ssinabulya I, et al. A cross-sectional study of hyponatraemia among elderly patients with heart failure in Uganda. BMJ Open 2016;6:e009775.

doi:10.1136/bmjopen-2015009775

- Prepublication history for this paper is available online. To view these files please visit the journal online (http://dx.doi.org/10.1136/ bmjopen-2015-009775).

Received 28 August 2015 Revised 24 March 2016 Accepted 6 April 2016

CrossMark

${ }^{1}$ Makerere University College of Health Sciences, Kampala, Uganda

${ }^{2}$ School of Public Health, University of Sydney, Sydney, Queensland, Australia

Correspondence to Dr Harriet Nankabirwa; harrietmay2001@yahoo.com

\section{ABSTRACT}

Background: Hyponatraemia is a common electrolyte disturbance among older patients. We determined the prevalence of and factors associated with hyponatraemia among older patients with predominantly acute decompensated heart failure attending a tertiary hospital in Kampala, Uganda.

Objectives: Main study aim: (1) to determine the prevalence of hyponatraemia among patients aged 60 years and above with heart failure attending Mulago National Referral Hospital; (2) to describe the factors associated with hyponatraemia among patients aged 60 years and above with heart failure attending Mulago National Referral Hospital.

Setting: The study was conducted in one tertiary hospital located in the northeast of Kampala, Uganda.

Participants: 400 adults aged 60 years and above were identified for the study. Of these, 188 were excluded as they did not fulfil the inclusion criteria and one declined to participate, leaving a final study group of 211 older adults aged 60 years and above, with a clinical diagnosis of heart failure using Framingham's criteria.

Results: The prevalence of hyponatraemia was $24.2 \%$ (51/211). Hyponatraemia was mainly found in patients with mild-to-moderate heart failure, New York Heart Association classes 2 and 3 . Of the 51 patients with hyponatraemia, $27(52.9 \%)$ had mild hyponatraemia, while $24(47.1 \%)$ had moderate to severe hyponatraemia of $130-125 \mathrm{mmol} / \mathrm{L}$. History of vomiting $(\mathrm{OR}=2.94,95 \%$ $\mathrm{Cl} 1.29$ to $6.70, \mathrm{p}=0.010$ ) and use of loop diuretics (OR=2.71, 95\% Cl 1.13 to $6.52, p=0.026$ ) were identified as independent factors associated with hyponatraemia among older patients with heart failure.

Conclusions: Our study revealed a relatively high prevalence of hyponatraemia among older patients with mild to moderate heart failure. Patients presenting with a history of vomiting from any cause or use of loop diuretics were more likely to have hyponatraemia.

\section{INTRODUCTION}

Heart failure is becoming more common in sub-Saharan Africa due to the epidemiological transition to non-communicable diseases, and the increasing numbers of older

\section{Strengths and limitations of this study}

- The results of this study can be generalised to similar settings in other countries in sub-Saharan Africa.

- The study was cross-sectional and so causal relationships cannot be established.

- The sample size was small for assessing factors associated with hyponatraemia and therefore weak associations may have been missed.

- Blood pressure measurements were taken only once, and so patients may have been misclassified as having hypertension.

people. The population of people aged 60 years and over is increasing in Uganda. ${ }^{12}$ Heart failure is a common observed health problem among older people in Uganda and elsewhere in sub-Saharan Africa, and is believed to be mainly caused by dilated cardiomyopathy, rheumatic heart disease, and hypertension. ${ }^{3}$

Older people are particularly sensitive to the development of various electrolyte abnormalities, especially hyponatraemia, which is a serum sodium level below $135 \mathrm{mmol} / \mathrm{L}^{4}{ }^{5}$ Serum sodium falls by about $1 \mathrm{mmol} / \mathrm{L}$ with each decade increase in age. ${ }^{6}$ Globally, $18-27 \%$ of all patients admitted to hospital with heart failure have hyponatraemia. ${ }^{7} 8$ As heart failure involves fluid retention in the body, it may lead to dilution hyponatraemia. In heart failure, diuretics normally are used to induce negative balance of sodium. Hyponatraemia is a potent predictor of poor outcome among older inpatients with heart failure. ${ }^{9}$ There is limited data on the burden of hyponatraemia and its complications in patients with heart failure in sub-Saharan Africa. To the best of our knowledge, the prevalence and factors associated with hyponatraemia among older adults with heart failure have not been studied in Uganda or any other sub-Saharan African countries. 


\section{MATERIALS AND METHODS}

We conducted a cross-sectional study between August 2013 and March 2014 to determine the prevalence of and factors associated with hyponatraemia among patients aged 60 years and above with heart failure. Patients were eligible for inclusion if they were: aged 60 years and above with a clinical diagnosis of either new onset (acute) or worsening (chronic) heart failure according to the Framingham criteria. ${ }^{10}$ Patients who could not follow the study procedures were excluded. We consecutively recruited 211 patients with predominately acute decompensated heart failure from the cardiac clinics and wards of Mulago National Referral Hospital and Uganda Heart Institute. Patients were considered to have decompensated heart failure if they had either two major or one major and two minor criteria present concurrently. ${ }^{10}$ The major criteria we considered in our study were: rales, neck vein distension, hepatojugular reflux, third heart sound and paroxysmal nocturnal dyspnoea. The minor criteria were: bilateral ankle oedema, nocturnal cough, hepatomegaly, dyspnoea on exertion and tachycardia. Both study sites are within the same location in the northeast of Kampala, the capital city of Uganda. Mulago National Referral Hospital is a public hospital offering services at no cost, and has the largest bed capacity in the country with about 1500 beds. The Uganda Heart Institute is an autonomous institution that offers private services to both adult and paediatric patients with heart conditions. It has a bed capacity of about 40 beds.

We informed all eligible patients about the study and the procedures involved; if they agreed to participate, we asked them to sign a consent form. We then ascertained the sociodemographic and clinical characteristics of the patients with a written questionnaire completed by the principal investigator or research assistant. The patients were specifically asked if their doctor had ever told them that they had diabetes mellitus, stroke, chronic kidney disease or hypertension. The care taker was asked of any recent behavioural changes in the patient, and the history was taken of current or previous medication use by the patient. A physical examination was carried out to ascertain weight, height, presence of pallor, oedema, hepatomegaly, raised jugular venous pressure, rales, gallop rhythm and the level of consciousness (mental alteration) using the Glasgow Coma scale. Blood pressures of patients were taken using a manual sphygmomanometer in either the lying down or sitting position depending on the functional status of the patient. Hypertension was defined as systolic blood pressure above $140 \mathrm{~mm} \mathrm{Hg}$ and/or diastolic blood pressure above $90 \mathrm{~mm} \mathrm{Hg}$.

Patients who met the study inclusion criteria fasted overnight, and at least $8 \mathrm{~h}$ and $2 \mathrm{~mL}$ of venous blood was withdrawn the next morning for measurement of sodium, chloride, potassium, sugar, lipids, creatinine and urea. The blood samples were centrifuged then mounted into the Cobas Integra 400 plus machine manufactured by Roche and analysed the same day in an accredited laboratory. A morning urine sample was collected for measurement of sodium, protein, sugar and presence of casts and red blood cells. Plasma and urine osmolality were calculated from the values obtained using the following formula:

Calculated osmolality $=2 \mathrm{Na}+($ serum/urine $)+$ Glucose (blood/urine)+Urea (all in $\mathrm{mmol} / \mathrm{L}$ ) .

Glomerular filtration rate (GFR) $\left(\mathrm{mL} / \mathrm{min} / 1.73 \mathrm{~m}^{2}\right)$ was calculated using Cockcroft-Gault formula: estimated GFR $=(140-$ Age $) \times$ weight $($ kilogram $) \times 0.85$ (in females $) /$ serum creatinine $(\mathrm{mg} / \mathrm{dL}) \times 72$.

Chronic kidney disease was classified as: stage 1 GFR $>90$, stage 2 GFR 60-89, stage 3 GFR 30-59, stage 4 GFR $15-29$ and stage 5 GFR $<15$. Most of the patients in this study had been previously hospitalised, and had had echocardiograms done; however, our study mainly focused on clinical diagnosis of heart failure using Framingham criteria. Given the fact that echocardiography is not readily available in most hospitals in Uganda, we used clinical criteria to increase applicability of the findings to a wide range of settings.

\section{Statistical analysis}

We used multivariate logistic regression analysis to study associations between predefined risk factors and hyponatraemia. All analyses were performed using STATA V.12.0. Variables with a $\mathrm{p}$ value $<0.05$ were considered statistically significant. For proportions, the sample size was calculated using the following formula $\mathrm{n}=\mathrm{N} / 1+\mathrm{N}(\mathrm{e})^{2}$ proposed by Yamane. ${ }^{11}$

Patients or care takers gave written informed consent to participate in the study. If a patient was found to have hyponatraemia, his/her clinician was informed and the patient was managed appropriately.

\section{RESULTS}

The sociodemographic and clinical characteristics of the 211 patients in the study are shown in table 1 . The largest group of patients was aged 60-69 years $(40.3 \%)$. The median (IQR) age of the patients was $70.0(65-77)$ years, with the oldest patient being 102 years old. Less than half of the study's patients were males $(n=81$, $38.4 \%)$. Most patients had been previously hospitalised for heart failure $(\mathrm{n}=148,70.1 \%)$ and had presented with worsening symptoms; $63(29.9 \%)$ of the patients were newly diagnosed with heart failure, with symptoms for less than a month. More than half $(\mathrm{n}=134,63.5 \%)$ of the patients were New York Heart Association (NYHA) class 2. Few of the patients $(n=52 / 211,24.6 \%)$ had smoked tobacco, and $90(42.7 \%)$ consumed alcohol at least occasionally. Forty-six study patients had high fasting blood sugar (21.8\%), and only one had high triglycerides.

Most of the 51 patients with hyponatraemia $(n=47$, $92.2 \%$ ) were NYHA classes 2 and 3, which is mild-moderate heart failure, as shown in table 1 . Very few of the 
Table 1 Sociodemographic and clinical characteristics of the study patients by serum sodium level

\begin{tabular}{|c|c|c|c|c|}
\hline \multirow[b]{2}{*}{ Characteristic } & \multirow[b]{2}{*}{ Overall $(n=211, \%)$} & \multicolumn{2}{|l|}{ Serum sodium level } & \multirow[b]{2}{*}{ p Value* } \\
\hline & & Hyponatraemia (n, \%) & Normal (135-150 mmol/L); (n, \%) & \\
\hline Age group (years) & & & & 0.828 \\
\hline $60-69$ & $85(40.3)$ & $20(23.5)$ & $65(74.5)$ & \\
\hline $70-79$ & $84(39.8)$ & $22(26.2)$ & $62(73.8)$ & \\
\hline$\geq 80$ & 42 (19.9) & 9 (21.4) & $33(78.6)$ & \\
\hline Sex & & & & 0.602 \\
\hline Female & $130(61.6)$ & $33(25.4)$ & $97(74.6)$ & \\
\hline Smoking & & & & 0.364 \\
\hline Yes & $52(24.6)$ & 15 (28.8) & 37 (71.2) & \\
\hline Salt intake & & & & 0.056 \\
\hline Yes & $192(91.0)$ & $43(22.4)$ & $149(77.6)$ & \\
\hline BMI, $n=151$ & & & & 0.283 \\
\hline Underweight & $18(11.9)$ & $4(22.2)$ & $14(77.8)$ & \\
\hline Normal & 87 (57.6) & 19 (21.8) & 68 (78.2) & \\
\hline Overweight & $34(22.5)$ & $3(8.8)$ & $31(91.2)$ & \\
\hline Obesity & $12(8.0)$ & $1(8.3)$ & $11(91.7)$ & \\
\hline NYHA & & & & 0.005 \\
\hline Class 1 & $1(0.5)$ & $1(100.0)$ & $0(0.0)$ & \\
\hline Class 2 & $134(63.5)$ & $23(17.2)$ & $111(82.8)$ & \\
\hline Class 3 & 70 (33.2) & 24 (34.3) & 46 (65.7) & \\
\hline Class 4 & $6(2.8)$ & $3(50.0)$ & $3(50.0)$ & \\
\hline Diabetes mellitus & & & & 0.120 \\
\hline Yes & $20(9.5)$ & $2(10.0)$ & $18(90.0)$ & \\
\hline Hypertension $n=207$ & & & & 0.024 \\
\hline Yes & $145(70.1)$ & $28(19.3)$ & $117(80.7)$ & \\
\hline Stroke & & & & 0.955 \\
\hline Yes & $8(3.8)$ & $2(25.0)$ & $6(75.0)$ & \\
\hline Chronic kidney disease & & & & 0.782 \\
\hline Yes & $7(3.3)$ & $2(28.6)$ & $5(71.4)$ & \\
\hline Seizures & & & & 0.223 \\
\hline Yes & $4(1.9)$ & $2(50.0)$ & $2(50.0)$ & \\
\hline Falls & & & & 0.012 \\
\hline Yes & $16(7.6)$ & $8(50.0)$ & $8(50.0)$ & \\
\hline Vomiting & & & & 0.006 \\
\hline Yes & $39(18.5)$ & $16(41.0)$ & $23(59.0)$ & \\
\hline Body weakness & & & & 0.224 \\
\hline Yes & 184 (87.2) & $47(25.5)$ & $137(74.5)$ & \\
\hline Medication history $n=210$ & & & & \\
\hline ACEi/ARB & & & & 0.510 \\
\hline Yes & $111(52.9)$ & $29(26.1)$ & $82(78.9)$ & \\
\hline Psychotropics & & & & 0.421 \\
\hline Yes & $2(1.0)$ & $0(00.0)$ & $2(100.0)$ & \\
\hline Thiazides diuretics & & & & 0.730 \\
\hline Yes & $22(10.5)$ & $6(27.3)$ & $16(72.7)$ & \\
\hline Loop diuretics & & & & 0.013 \\
\hline Yes & $134(63.8)$ & $40(29.9)$ & $94(70.1)$ & \\
\hline Potassium sparing diuretic & & & & 0.069 \\
\hline Yes & $36(17.1)$ & $13(36.1)$ & $23(63.9)$ & \\
\hline
\end{tabular}

211 patients in the study presented with clinical characteristics suggestive of hyponatraemia such as seizures $(\mathrm{n}=4,1.9 \%)$, falls $(\mathrm{n}=16,7.6 \%)$, abnormal behaviour $(n=9,4.3 \%)$, altered mentation $(n=26,12.3 \%)$ and vomiting $(\mathrm{n}=39,18.5 \%)$. Sixteen of the 51 patients with hyponatraemia presented with vomiting and most likely had hypovolaemic hyponatraemia, while the remaining 35 patients had dilutional hyponatraemia.

The majority $(\mathrm{n}=118,55.9 \%)$ of the 211 study patients were known to have hypertension and 7 were known to have chronic kidney disease (3.3\%), as shown in table 1. More than three-quarters of the patients were using at 
least one medicine $(n=165,78.2 \%)$, with the majority using loop diuretics $(n=134,81.2 \%)$. Forty of the 134 patients $(29.9 \%)$ using loop diuretics had hyponatraemia. We did not analyse differences among the different loop diuretics. Of the 211 study patients, only 22 $(10.5 \%)$ used thiazide diuretics; of these, $6(27.3 \%)$ had hyponatraemia. Only two of the study patients used psychotropic drugs (amitriptyline and carbamazepine). More than three-quarters of the study patients $(n=192$, 91.0\%) added salt to their food, and 43 of these patients (22.4\%) had hyponatraemia. Most $(19,70.4 \%)$ of the patients with hyponatraemia had a normal body mass index which was different from other studies where low body mass index has been associated with hyponatraemia. ${ }^{12}$

Among the 211 patients in the study, $(n=51,24.2 \%)$ had hyponatraemia with serum sodium below $135 \mathrm{mmol} / \mathrm{L}$. At a serum level of $130 \mathrm{mmol} / \mathrm{L}$ and below, the prevalence of hyponatraemia was $11.0 \%$ and at a serum sodium level below $125 \mathrm{mmol} / \mathrm{L}$ (severe hyponatraemia), the prevalence of hyponatraemia was $5.7 \%$. Of the 51 patients with hyponatraemia, more than half had mild hyponatraemia, serum sodium between 135 and $130 \mathrm{mmol} / \mathrm{L}(\mathrm{n}=27,52.9 \%)$.

Forty-three $(93.5 \%)$; of the patients with hyponatraemia were losing sodium in their urine but all study patients had normal spot urine osmolality. As shown in table 2, according to the calculated Glomerular Filtration Rate, $62.4 \%$ of patients $(n=98 / 157)$ had chronic kidney disease and $31.4 \%(\mathrm{n}=16 / 51)$ had hyponatraemia. Many $(\mathrm{n}=74,47.1 \%)$ of the 157 patients had stage 3 kidney disease. In total, 114 (54.0\%) of the study patients had high calculated plasma osmolality; only 4 of these patients had hyponatraemia.

The statistically significant factors associated with hyponatraemia were use of loop diuretics $(\mathrm{OR}=2.51$, $95 \%$ CI 1.20 to $5.26, \mathrm{p}=0.01)$, vomiting $(\mathrm{OR}=2.72,95 \%$ CI 1.30 to $5.70, \mathrm{p}=0.01)$, falls $(\mathrm{OR}=3.53,95 \%$ CI 1.25 to 9.97, $\mathrm{p}=0.02)$, abnormal behaviour $(\mathrm{OR}=6.98,95 \%$ CI 1.68 to $29.01, \mathrm{p}=0.01)$ and altered mentation $(\mathrm{OR}=3.21$, $95 \%$ CI 1.37 to $7.49, \mathrm{p}=0.01$ ), as shown in table 2 . High-blood pressure was associated with a decrease in odds of hyponatraemia (OR=0.47, 95\% CI 0.24 to 0.91 , $\mathrm{p}=0.03$ ).

In multivariate analysis, only vomiting $(\mathrm{OR}=2.94,95 \%$ CI 1.29 to $6.70, \mathrm{p}=0.010$ ) and taking loop diuretics $(\mathrm{OR}=2.71,95 \%$ CI 1.13 to $6.52, \mathrm{p}=0.026)$ were found to be statistically significantly associated with hyponatraemia (see table 3$)$. There was also a suggestion $(p=0.077)$ that high-blood pressure was inversely associated with hyponatraemia (OR=0.51, 95\% CI 0.25 to 1.07 ).

\section{DISCUSSION}

In the past, heart failure was an uncommon condition among older people in sub-Saharan Africa because of low life expectancy and low prevalence of noncommunicable diseases. Life expectancy has now improved with more people living past 60 years of age. We were, therefore, able to collect a large sample size of 211 older patients with heart failure in one large hospital in Uganda in the short period of 7 months.

The results of our study show a relatively high prevalence of hyponatraemia (24.2\%) in Uganda among patients aged 60 years and above, with mainly mild to moderate heart failure NYHA classes 2 and 3. This finding is different from previous studies carried out in developed countries where hospitalised older patients had a much lower prevalence of hyponatraemia ranging from $7 \%$ to $12 \% .{ }^{43}$ Hyponatraemia is a marker of poor prognosis for heart failure and is associated with longer hospital stays, and high inhospital and early postdischarge mortality. ${ }^{14-16}$ To the best of our knowledge, there have been no other studies of hyponatraemia among patients with heart failure in sub-Saharan Africa.

Low salt intake predisposes to hyponatraemia. In our study, nearly all patients $(91.0 \%)$ added salt to their food. In other studies it been found that some older people add very little salt to their food, predisposing them to hyponatraemia. ${ }^{17}$ Patients with hyponatraemia in our study were more likely to present with altered mentation, abnormal behaviour and falls, as found in studies by Adrogué et al and Cumming et al. ${ }^{18-20}$

Our study found that many patients presented with generalised body weakness $(87.2 \%)$, headache $(23.2 \%)$, altered mentation $(12.3 \%)$, and vomiting $(18.5 \%)$. The clinical presentation was similar across all the classes of hyponatraemia (mild, moderate, severe). However, in studies carried out elsewhere, patients with mild hyponatraemia tended to be asymptomatic, ${ }^{21}$ while those with moderate hyponatraemia tended to have anorexia, nausea, and headache $;^{21}$ those with severe hyponatraemia had confusion, coma, seizures or death. ${ }^{21} 22$ These clinical presentations are in keeping with the central nervous system effects of hyponatraemia. In general, older chronically ill patients with hyponatraemia develop more symptoms than younger otherwise healthy patients. Symptoms also tend to be more severe when the onset of hyponatraemia is rapid and when the effective plasma osmolality falls to $<240 \mathrm{mOsm} / \mathrm{kg}$. Symptoms of hyponatraemia can be subtle and consist mainly of changes in mental state, including altered personality, lethargy, and confusion. As the serum sodium falls to $<115 \mathrm{mEq} / \mathrm{L}$, stupor, neuromuscular hyperexcitability, hyper-reflexia, seizures and coma occur. ${ }^{23}$

The majority of the patients in our study were known to have hypertension $(55.9 \%)$ which is a similar finding to that in a study conducted by Achadu in Uganda, in 2002 (unpublished data). Most patients $(78.2 \%)$ in our study were on medication for heart failure, hypertension, and other comorbidities; with the majority using loop diuretics (62.5\%) and either ACE inhibitors or Angiotensin 11 receptor blockers (52.9\%), which increase sodium loss in urine.

Plasma osmolality, blood pressure, and cardiac output determine the release of vasopressin from the pituitary 
Table 2 Unadjusted ORs for associations between sociodemographic, clinical characteristics and hyponatraemia

\begin{tabular}{|c|c|c|c|c|}
\hline \multirow[b]{2}{*}{ Characteristic } & \multicolumn{2}{|c|}{ Serum sodium level } & \multirow[b]{2}{*}{ Crude OR $(95 \% \mathrm{Cl})$} & \multirow[b]{2}{*}{ p Value } \\
\hline & $\begin{array}{l}\text { Hyponatraemia } \\
\mathrm{N}(\%)\end{array}$ & $\begin{array}{l}\text { Normal } \\
\text { N (\%) }\end{array}$ & & \\
\hline Age (years) & & & & 0.83 \\
\hline $60-69$ & $20(39.2)$ & $65(40.6)$ & 1 & \\
\hline $70-79$ & $22(43.1)$ & $62(38.8)$ & 1.15 (0.57 to 2.32$)$ & \\
\hline$\geq 80$ & $9(17.7)$ & $33(20.6)$ & 0.89 (0.36 to 2.16$)$ & \\
\hline Sex & & & & 0.60 \\
\hline Male & $18(35.3)$ & $63(39.4)$ & 1 & \\
\hline Female & $33(64.7)$ & 97 (60.6) & $0.84(0.44$ to 1.62$)$ & \\
\hline \multicolumn{5}{|l|}{ GFR, $n=157$} \\
\hline Stage 1 & $5(17.9)$ & $18(13.9)$ & 1 & \\
\hline Stage 2 & $7(25.0)$ & $29(22.5)$ & $0.87(0.24$ to 3.16$)$ & 0.69 \\
\hline Stage 3 & $11(39.3)$ & $63(48.8)$ & $0.63(0.19$ to 2.05$)$ & \\
\hline Stage 4 & $2(7.1)$ & $13(10.1)$ & 0.55 (0.09 to 3.31$)$ & \\
\hline Stage 5 & $3(10.7)$ & $6(4.7)$ & $1.80(0.33$ to 9.89$)$ & \\
\hline Falls & & & & 0.02 \\
\hline No & $43(84.3)$ & $152(95.0)$ & 1 & \\
\hline Yes & 8 (15.7) & $8(5.0)$ & 3.53 (1.25 to 9.97$)$ & \\
\hline Altered mentation & & & & 0.01 \\
\hline No & $39(76.5)$ & $146(91.3)$ & 1 & \\
\hline Yes & $12(23.5)$ & $14(8.7)$ & 3.21 (1.37 to 7.49 ) & \\
\hline Abnormal behaviour & & & & 0.01 \\
\hline No & $45(88.2)$ & $157(98.1)$ & 1 & \\
\hline Yes & $6(11.8)$ & $3(1.9)$ & 6.98 (1.68 to 29.01$)$ & \\
\hline Salt intake & & & & 0.07 \\
\hline No & 8 (15.7) & $11(6.9)$ & 1 & \\
\hline Yes & $43(84.3)$ & $149(93.1)$ & $0.40(0.15$ to 1.05$)$ & \\
\hline Vomiting & & & & 0.01 \\
\hline No & 35 (68.6) & $137(85.6)$ & 1 & \\
\hline Yes & $16(31.4)$ & $23(14.4)$ & 2.72 (1.30 to 5.70$)$ & \\
\hline Diabetes mellitus & & & & 0.09 \\
\hline No & $49(96.1)$ & $142(88.7)$ & 1 & \\
\hline Yes & $2(3.9)$ & $18(11.3)$ & $3.10(0.69$ to 13.87$)$ & \\
\hline Stroke & & & & 0.95 \\
\hline No & $49(96.1)$ & 154 (96.2) & 1 & \\
\hline Yes & $2(3.9)$ & $6(3.8)$ & 0.95 (0.19 to 4.88$)$ & \\
\hline CKD & & & & 0.79 \\
\hline No & $49(96.1)$ & 155 (96.9) & 1 & \\
\hline Yes & $2(3.9)$ & $5(3.1)$ & $0.79(0.15$ to 4.20$)$ & \\
\hline Loop diuretics & & & & 0.01 \\
\hline No & $11(21.6)$ & 65 (40.9) & 1 & \\
\hline Yes & $40(78.4)$ & $94(59.1)$ & 2.51 (1.20 to 5.26$)$ & \\
\hline Potassium sparing & & & & 0.08 \\
\hline No & $38(74.5)$ & $136(85.5)$ & 1 & \\
\hline Yes & $13(25.5)$ & $23(14.5)$ & $2.02(0.94$ to 4.36$)$ & \\
\hline$B P, n=207$ & & & & 0.03 \\
\hline Normal & $21(42.9)$ & $41(25.9)$ & 1 & \\
\hline High & $28(57.1)$ & $117(74.1)$ & $0.47(0.24$ to 0.91$)$ & \\
\hline
\end{tabular}

gland. Vasopressin is a hormone that causes retention of sodium and water. In heart failure, there is inappropriate and continued release of vasopressin due to reduced cardiac output despite a normal or reduced osmolality and this leads to hyponatraemia. Hyponatraemia in heart failure can also be due to maladaptive neurohormonal and renal changes, and diuretic treatment. ${ }^{15}$
In our study, hyponatraemia was more frequent in patients with renal failure and among those using diuretics.

We found that use of diuretics and vomiting was independently associated with hyponatraemia among older patients with heart failure in Uganda. Use of loop diuretics was the factor most strongly associated with 
Table 3 Age and sex-adjusted ORs for characteristics associated with hyponatraemia

\begin{tabular}{lll}
\hline Characteristic & Adjusted OR (95\% CI) & p Value* \\
\hline Vomiting & $2.94(1.29$ to 6.70$)$ & 0.010 \\
Falls & $2.45(0.72$ to 8.38$)$ & 0.153 \\
Altered mentation & $1.91(0.65$ to 5.60$)$ & 0.336 \\
Abnormal behaviour & $3.44(0.59$ to 20.18$)$ & 0.171 \\
Loop diuretics & $2.71(1.13$ to 6.52$)$ & 0.026 \\
Potassium sparing & $1.46(0.61$ to 3.49$)$ & 0.390 \\
High-blood pressure & $0.51(0.25$ to 1.07$)$ & 0.077 \\
${ }^{*} \chi^{2}$. & &
\end{tabular}

hyponatraemia in our study. This is different from studies in developed countries which have found that thiazides are the diuretic most strongly associated with hyponatraemia. $^{12}{ }^{15}{ }^{24}$ In Uganda, loop diuretics are more commonly used than thiazide diuretics for symptom relief in patients with heart failure, both for inpatients and outpatients. This is because loop diuretics are more readily available and more affordable. Loop diuretics act at the ascending loop of Henle of the kidney tubule by inhibiting the sodium-potassium-chloride channel leading to salt wasting, while thiazide diuretics inhibit the sodium-chloride co-transporter at the distal convoluted tubule by blocking sodium re-absorption by the tubular cells. Vomiting was a factor found to be associated with hyponatraemia in our study. This may have been due to other undiagnosed comorbidities like infections or side effects of the drugs the patients were using.

\section{Study limitations}

A number of potential limitations need to be acknowledged. We used Framingham's criteria for the clinical diagnosis of heart failure without echocardiography, and so we were unable to identify patterns of heart failure. The majority of study patients had been previously hospitalised and had had echocardiograms; however, we were unable to perform repeat echocardiograms for this study because of limited availability and very high cost at the study hospital. ${ }^{25}$ We were also unable to assess fluid intake because the patients used different size containers to drink fluids. Other limitations included the fact: (1) that our study was cross-sectional and so causal relationships cannot be established, and (2) that the sample size was small for assessing factors associated with hyponatraemia and therefore weak associations may have been missed. Finally, blood pressure measurements were taken only once; thus, patients may have been misclassified as having hypertension because of factors like 'white coat' fear or recent caffeine consumption.

\section{Study strength}

We recruited a consecutive series of patients at a large teaching hospital in Uganda. We believe that our results can be generalised to similar settings in other countries in sub-Saharan Africa.

\section{CONCLUSION}

Hyponatraemia is a common electrolyte abnormality among older patients in Uganda with mild to moderate heart failure and is strongly associated with use of loop diuretics. Both parenteral and oral loop diuretics are widely used in Uganda for symptom relief in acute decompensated heart failure. They are cheap and available in urban and rural areas of the country.

All older patients with heart failure and other comorbidities should have their serum sodium level monitored to avert the adverse outcomes associated with hyponatraemia. Older patients with heart failure should have health education about fluid restriction. There is a need to carry out a similar study among community-dwelling older adults to determine the prevalence and factors associated with hyponatraemia.

Acknowledgements The authors would like to thank all the older patients with heart failure who agreed to participate in this study, and the research assistants who collected the blood and urine samples and obtained the consent from the patients and care takers. The authors thank the Rainer Arhnold Senior House Officer's teaching support (RASHOTS) for accepting to be the conduit for the research funds.

Contributors ETK and HN developed the concept for the study. HN contributed by collecting and entering the data. SL analysed the data. HN, RGC, RK and IS contributed by writing the manuscript. All the authors approved the final version of the manuscript.

Funding Research reported in this publication was supported by the University of Sydney and the Fogarty International Center, the National Heart Lung and Blood Institute, and the Common Fund of the National Institutes of Health under Award Number R24 TW008861. The content is solely the responsibility of the authors and does not necessarily represent the official views of the funders. The funders had no role in study design, data collection and analysis, decision to publish, or preparation of the manuscript.

Competing interests None declared.

Ethics approval Makerere University College of Health Sciences Institution Review Board.

Provenance and peer review Not commissioned; externally peer reviewed.

Data sharing statement No additional data are available.

Open Access This is an Open Access article distributed in accordance with the Creative Commons Attribution Non Commercial (CC BY-NC 4.0) license, which permits others to distribute, remix, adapt, build upon this work noncommercially, and license their derivative works on different terms, provided the original work is properly cited and the use is non-commercial. See: http:// creativecommons.org/licenses/by-nc/4.0/

\section{REFERENCES}

1. $\mathrm{MoH}$. Promoting peoples health to enhance socio-economic development. Health sector strategic \& investiment plan. Kampala: $\mathrm{MoH}, 2010: 30-1$.

2. Bureau USC. International Programs. International programsInformation Gateway-USCensusgov. https://wwwcensusgov/ population/international/data/idb/informationGatewayphp2016

3. Sliwa K, Damasceno A, Mayosi BM. Epidemiology and etiology of cardiomyopathy in Africa. Circulation 2005;112:3577-83.

4. Luckey AE, Parsa CJ. Fluid and electrolytes in the aged. Arch Surg 2003;138:1055-60.

5. Tareen N, Martins D, Nagami G, et al. Sodium disorders in the elderly. J Natl Med Assoc 2005;97:217-24.

6. Miller M. Hyponatremia in the elderly: risk factors, clinical consequences, and management. Clin Geriatr 2009;17:34-9.

7. Klein L, O'Connor CM, Leimberger JD, et al. Lower serum sodium is associated with increased short-term mortality in hospitalized patients with worsening heart failure: results from the outcomes of a 
prospective trial of intravenous milrinone for exacerbations of chronic heart failure (OPTIME-CHF) study. Circulation 2005;111:2454-60.

8. Leier CV, Dei Cas L, Metra M. Clinical relevance and management of the major electrolyte abnormalities in congestive heart failure: hyponatremia, hypokalemia, and hypomagnesemia. Am Heart $J$ 1994;128:564-74.

9. Balling L, Schou M, Videbaek L, et al. Prevalence and prognostic significance of hyponatraemia in outpatients with chronic heart failure. Eur J Heart Fail 2011;13:968-73.

10. Ho KK, Pinsky JL, Kannel WB, et al. The epidemiology of heart failure: the Framingham Study. J Am Coll Cardiol 1993;22: A6-13.

11. Yamane T. Statistics; an introductory analysis. New York: Harper and Row, 1967.

12. Sonnenblick M, Friedlander $Y$, Rosin AJ. Diuretic-induced severe hyponatremia. Review and analysis of 129 reported patients. Chest J 1993;103:601-6.

13. Fusgen I. Disorders of water and sodium metabolism in older patients. Eur J Geriatr 2003. http://www.saltassociation.co.uk/wp/wpcontent/uploads/IFusgen-Disordersofwaterandsodiummetabolism inolderpatients1.pdf

14. Gheorghiade M, Abraham WT, Albert NM, et al. Relationship between admission serum sodium concentration and clinical outcomes in patients hospitalized for heart failure: an analysis from the OPTIMIZE-HF registry. Eur Heart $J$ 2007;28:980-8.
15. Romanovsky A, Bagshaw S, Rosner MH. Hyponatremia and congestive heart failure: a marker of increased mortality and a target for therapy. Int J Nephrol 2011;2011:732746.

16. Abraham WT, Fonarow GC, Albert NM, et al. Predictors of in-hospital mortality in patients hospitalized for heart failure: insights from the Organized Program to Initiate Lifesaving Treatment in Hospitalized Patients with Heart Failure (OPTIMIZE-HF). J Am Coll Cardiol 2008;52:347-56.

17. Association ESP. Salt and Elderly Forum. 2007. http://www.eusalt.com

18. Boscoe A, Paramore C, Verbalis JG. Cost of illness of hyponatremia in the United States. Cost Eff Resour Alloc 2006;4:10.

19. Adrogué HJ. Consequences of inadequate management of hyponatremia. Am J Nephrol 2005;25:240-9.

20. Cumming K, Hoyle GE, Hutchison JD, et al. Prevalence, incidence and etiology of hyponatremia in elderly patients with fragility fractures. PLOS ONE 2014;9:e88272.

21. Thompson CJ. Hyponatraemia: new associations and new treatments. Eur J Endocrinol 2010;162:S1-3.

22. Deitelzweig SB, McCormick L. Hyponatremia in hospitalized patients: the potential role of tolvaptan. Hospital Practice, 2011

23. Adrogué HJ, Madias NE. Hyponatremia. N Engl J Med 2000;342:1581-9.

24. Liamis G, Elisaf M. Hyponatremia induced by drugs. In: Simon EE, ed. Hyponatremia. New York: Springer, 2013:111-26.

25. Grimaldi A, Ammirati E, Karam N, et al. Cardiac surgery for patients with heart failure due to structural heart disease in Uganda: access to surgery and outcomes. Cardiovasc J Afr 2014;25:204. 